\title{
Effects of Slight Non-Stoichiometry in Sm-Ba-Cu-O Systems on Superconducting Characteristics
}

\author{
J. Maňka, A. Cigáň, J. Polovková, A. Koňakovský, A. Prnová \\ Institute of Measurement Science, Slovak Academy of Sciences, Dúbravská cesta 9, 84104 Bratislava, Slovakia \\ e-mail: jan.manka@savba.sk
}

\begin{abstract}
We studied the effects of slight Sm-Ba non-stoichiometry in Sm-Ba-Cu-O superconducting compounds on their transition, structural, and magnetic properties. Two series of single-phase samples of $\mathrm{Sm}_{1+x} \mathrm{Ba}_{2-x} \mathrm{Cu}_{3} \mathrm{O}_{7+\delta}$ and $\mathrm{Sm}_{1-x} \mathrm{Ba}_{2+x} \mathrm{Cu}_{3} \mathrm{O}_{7+\delta}$ with composition deviation from stoichiometry $x$ from 0 to 0.1 were synthesized by the solid-state reaction method from $\mathrm{Sm}_{2} \mathrm{O}_{3}, \mathrm{BaCO}_{3}$ and $\mathrm{CuO}$ precursors and sintered at the temperature of $\sim 1060{ }^{\circ} \mathrm{C}$ in flowing oxygen. All samples showed the values of $T_{\mathrm{c}}>90 \mathrm{~K}$ and the volume density, $\rho, 6.45 \mathrm{~g} \mathrm{~cm}^{-3}<\rho \leq 6.73 \mathrm{~g} \mathrm{~cm}^{-3}$. The effect of the composite deviation of $x$ on $T_{\mathrm{c}}, \Delta T_{\mathrm{c}}$, and volume magnetization $M$ was studied. For $\mathrm{Sm}_{1+x} \mathrm{Ba}_{2-x} \mathrm{Cu}_{3} \mathrm{O}_{7+\delta}$ compounds, optimal values of $x$ were determined to maximize the width of the magnetization hysteresis at higher values of the applied magnetic field, corresponding mainly to the grain contribution. We also prepared the $\mathrm{Sm}_{1+x} \mathrm{Ba}_{2} \mathrm{Cu}_{3} \mathrm{O}_{7+\delta}$ samples with $x$ from 0 to 0.1 using the same processing conditions as in the case of $\mathrm{A}$ and $\mathrm{B}$ series. For the $\mathrm{Sm}_{1+\chi} \mathrm{Ba}_{2} \mathrm{Cu}_{3} \mathrm{O}_{7+\delta}$ samples, values of $x=0.02-0.03$ optimize $T_{c}, \Delta T_{c}, H_{\mathrm{p} 1}$ as well as $M$.
\end{abstract}

Keywords: Superconductors, Sm-123, cation non-stoichiometry, critical temperature, magnetization

\section{INTRODUCTION}

$\mathrm{T}$ HE $\mathrm{REBa}_{2} \mathrm{Cu}_{3} \mathrm{O}_{7}(\mathrm{RE} 123 ; \mathrm{RE}=$ rare earth including $\mathrm{Y})$ superconducting systems are promising materials for high-field power applications at high temperatures, advantageous for the synthesis of superconducting bulks and also tape and wire conductors. The systems, where RE represents the so-called light rare-earth elements (LRE) like $\mathrm{La}, \mathrm{Nd}, \mathrm{Sm}, \mathrm{Eu}$, are particularly interesting. It is well known that in the LRE-123 systems, the $\mathrm{LRE}^{3+}$ ions can occupy the $\mathrm{Ba}^{2+}$ sites because the ion radius of the elements is nearest to the ion radius of the $\mathrm{Ba}$ ion. It was reported that the increasing occupation of $\mathrm{Ba}^{2+}$ sites resulted in a deterioration of superconducting properties, e.g. critical transition temperature, $T_{c}$, mainly at high LRE-Ba substitution levels [1-6]. It is also known that synthesis at reduced oxygen partial pressures or addition of $\mathrm{Ba}$-excess (in the form of such precursors as $\mathrm{BaO}, \mathrm{BaO}_{2}, \mathrm{BaCuO}_{x}$ etc.) can effectively suppress the substitution and therefore the formation of solid solutions of the $\mathrm{LRE}_{1+x} \mathrm{Ba}_{2-x} \mathrm{Cu}_{3} \mathrm{O}_{y}$ type. On the other hand, for the melt-textured samples or single crystals, local composition fluctuations, known as nanoclusters, were observed, consisting of the $\mathrm{LRE}_{1+\chi} \mathrm{Ba}_{2}$ ${ }_{x} \mathrm{Cu}_{3} \mathrm{O}_{y}$ phase. The $10-50 \mathrm{~nm}$ dimension nanoclusters may work as highly effective pinning centres at higher magnetic fields, [7-9]. Oh et al. [10] reported that higher critical current densities, $j_{c}$, of $\mathrm{Sm}-\mathrm{Ba}-\mathrm{Cu}-\mathrm{O}$ coated conductors were obtained in the Sm-rich, Ba-poor and $\mathrm{Cu}$-rich composition regions, as compared to the stoichiometric region. Moreover, for PLD YBCO films, it was also reported that additions of rare earths in excess were effective in improving $j_{\mathrm{c}}$ by producing nanoparticulate pinning centres [11-13].

Thus, a detailed study of non-stoichiometry in LRE-Ba-Cu$\mathrm{O}$ compounds is important for the progress in the development of single-domain bulks or in the second generation coated conductors based on LRE-Ba-Cu-O high $T_{\mathrm{c}}$ superconductors. It is interesting to study non- stoichiometry in $\mathrm{LRE}_{1+\mathrm{x}} \mathrm{Ba}_{2-\mathrm{x}} \mathrm{Cu}_{3} \mathrm{O}_{7+\delta}$ systems, namely in the range of slight composition deviations. Moreover, no systematic study of the systems has been performed yet and it should be noted that their properties are strongly dependent on technological procedure parameters.

There are several results of a study of non-stoichiometry in $\mathrm{Sm}_{1+x} \mathrm{Ba}_{2-x} \mathrm{Cu}_{3} \mathrm{O}_{\mathrm{y}}$ systems, however, most of them focused on higher composition ranges of $x[6,14,15]$. Sometimes, discrepant results were obtained, as in the case of orthorhombic-tetragonal phase transition [14, 15], but it may have been due to different processing conditions. Nevertheless, a decrease of $T_{\mathrm{c}}$ and increase of the room temperature resistivity with an increasing deviation were usually observed, especially at higher substitution level of $x$. In our former work [16], we studied slight nonstoichiometric bulk sintered samples of $\mathrm{Eu}_{1+\chi} \mathrm{Ba}_{2-x} \mathrm{Cu}_{3} \mathrm{O}_{7+\delta}$, and $\mathrm{Eu}_{1-x} \mathrm{Ba}_{2+x} \mathrm{Cu}_{3} \mathrm{O}_{7+\delta}$ samples for $0 \leq x \leq 0.1$. In this work, we prepared two series of slight non-stoichiometric bulk samples of $\mathrm{Sm}_{1+x} \mathrm{Ba}_{2-x} \mathrm{Cu}_{3} \mathrm{O}_{7+\delta}$, (A) and $\mathrm{Sm}_{1-x} \mathrm{Ba}_{2+x} \mathrm{Cu}_{3} \mathrm{O}_{7+\delta}$, (B), respectively, and investigated composition deviation effects on their superconducting, structural, and mainly magnetic properties.

\section{EXPERIMENTAL}

Samples of the A and B series, where $x=0,0.01,0.02$, $0.04,0.05,0.07$ and 0.1 were prepared by a standard solidstate reaction method using commercial high-purity oxide powders of $\mathrm{Sm}_{2} \mathrm{O}_{3}(99.99 \%), \mathrm{CuO}(99.99 \%)$, and $\mathrm{BaCO}_{3}$ $(99.99 \%)$. Prior to weighing and mixing, the $\mathrm{Sm}_{2} \mathrm{O}_{3}$ powder was preannealed at $1100{ }^{\circ} \mathrm{C}$ for more than $5 \mathrm{~h}$ in air to release contaminations, e.g. moisture. Here it would be appropriate to say that some useful information about the thermal decomposition behaviour properties and the role of other $\mathrm{BaCO}_{3}$ and $\mathrm{CuO}$ precursors can be obtained, e.g. [17]. Thereafter, the powders were carefully weighed in appropriate weight amounts, manually homogenized in acetone in an agate mortar for five minutes, put into alumina 
crucibles and calcined at $930{ }^{\circ} \mathrm{C}$ for 40 hours in air. The obtained precursors were again homogenized, pressed into pellets (with the diameter of $12 \mathrm{~mm}$ ) and sintered in a horizontal tube furnace in flowing oxygen $(10 \mathrm{ml} / \mathrm{min})$ at about $1060^{\circ} \mathrm{C}$ for $72 \mathrm{~h}$, then cooled to $520^{\circ} \mathrm{C}$ and held at this temperature for $24 \mathrm{~h}$, and thereafter cooled in the furnace to room temperature. Several A and B series were repeatedly prepared in the same thermal cycle. In this paper, some characteristic results are reported. The critical temperature, $T_{\mathrm{c}}(R=0)$, of the samples was determined by a standard resistance four-point method and the transition width, $\Delta T_{\mathrm{c}}$, was characterized by the $10-90 \%$ criterion. The distance of the voltage contact points of all samples was approximately the same. The temperature measurement uncertainty was less than $0.2 \mathrm{~K}$. The phase composition was studied by $\mathrm{X}$ ray diffraction measurements ( $\mathrm{CuK} \alpha$ radiation). $\mathrm{AC}$ and virgin volume magnetization characteristics were measured by a compensation method using the second-order SQUID gradiometer [18]. All magnetization characteristics of the samples were measured at $\sim 77 \mathrm{~K}$ after zero-field cooling. The applied magnetic field, $H_{\mathrm{a}}$, was parallel to the sample axis. The first penetration magnetic field, $H_{\mathrm{pl}}$, characterizing the intergrain weak link network, was determined as a value of the applied field corresponding to deflection of the linear behavior of the virgin magnetization curves in the region of the full Meissner shielding of the entire sample corrected to the demagnetizing factor determined from the sample geometry.

\section{RESUlTS AND DISCUSSION}

From the X-ray diffraction data, we can conclude that all samples in A and B groups are single-phase. It was impossible to identify any impurity phase within the limit of the resolution. The XRD patterns of some samples of $\mathrm{Sm}_{1+x} \mathrm{Ba}_{2-x} \mathrm{Cu}_{3} \mathrm{O}_{y}$ series are shown in Fig. 1 .

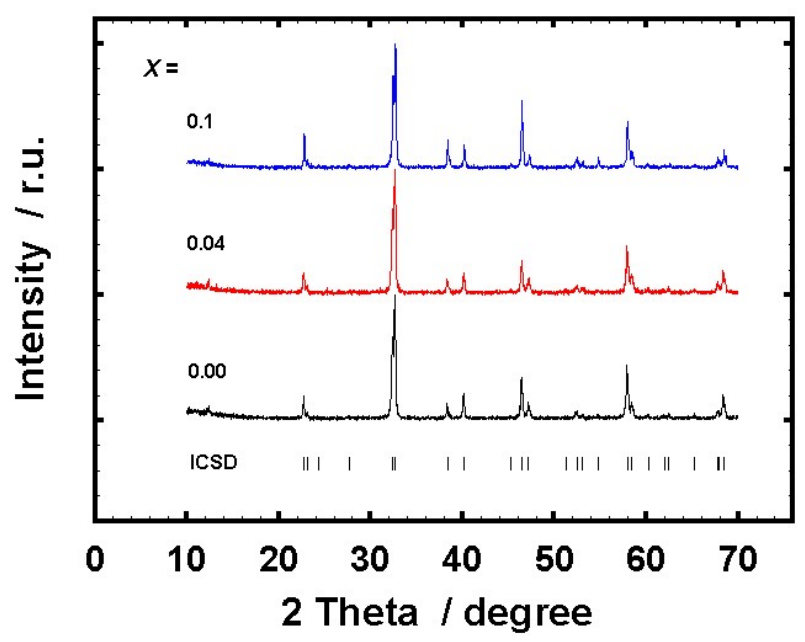

Fig.1. XRD patterns of $\mathrm{Sm}_{1+\chi} \mathrm{Ba}_{2-x} \mathrm{Cu}_{3} \mathrm{O}_{7+\delta}$ samples with different $x$ values.

The non-stoichiometry of A and B samples has no significant effect on resistance, $R$, vs. temperature, $T$, dependences in the studied range, $x$. All samples show the linear temperature dependence of the normal state $R$ in a broad temperature range. However, for a higher $x$, a weak trend of an increase of the normal state $R$ and deviations from the linear dependence could have been observed. The $R$ vs. $T$ dependences of $\mathrm{Sm}_{1-x} \mathrm{Ba}_{2+\chi} \mathrm{Cu}_{3} \mathrm{O}_{7+\delta}$ samples are shown in Fig. 2.

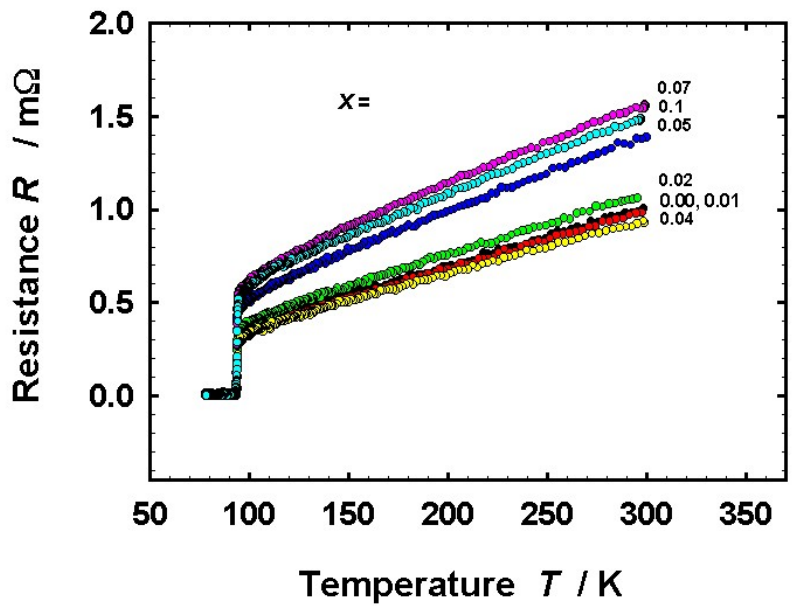

Fig.2. $R$ vs. $T$ dependences of the $\mathrm{Sm}_{1-\chi} \mathrm{Ba}_{2+x} \mathrm{Cu}_{3} \mathrm{O}_{7+\delta}$ samples.

Changes of $T_{\mathrm{c}}$ and $\Delta T_{\mathrm{c}}$ vs. $x$ are shown in Fig. 3 and Fig. 4 , respectively. While $T_{\mathrm{c}}$ of the $\mathrm{Sm}_{1-\mathrm{x}} \mathrm{Ba}_{2+\mathrm{x}} \mathrm{Cu}_{3} \mathrm{O}_{7+\delta}$ samples changes only slightly, $T_{\mathrm{c}}$ of the A samples decreases notably, when $\mathrm{x}$ increases. However, it is still higher than 90 $\mathrm{K}$. The results are consistent with the observed increase in the oxygen content, if $\mathrm{LRE}^{3+}$ ions substitute $\mathrm{Ba}^{2+}$ ions and with increasing the oxygen disordering [19]. Sano et al. studied the effect of the substitution of $\mathrm{Sm}$ for $\mathrm{Ba}$ in $\mathrm{Sm}_{1+\chi} \mathrm{Ba}_{2-x} \mathrm{Cu}_{3} \mathrm{O}_{7+\delta}$ sintered samples $(0 \leq x \leq 2)$ [4]. They reported the maximum value of the critical temperature of $94 \mathrm{~K}$ for $x=0.02$ and a much lower value than observed by us, specifically, about $80 \mathrm{~K}$ for $x=0.1$. This difference may be ascribed to different processing conditions.

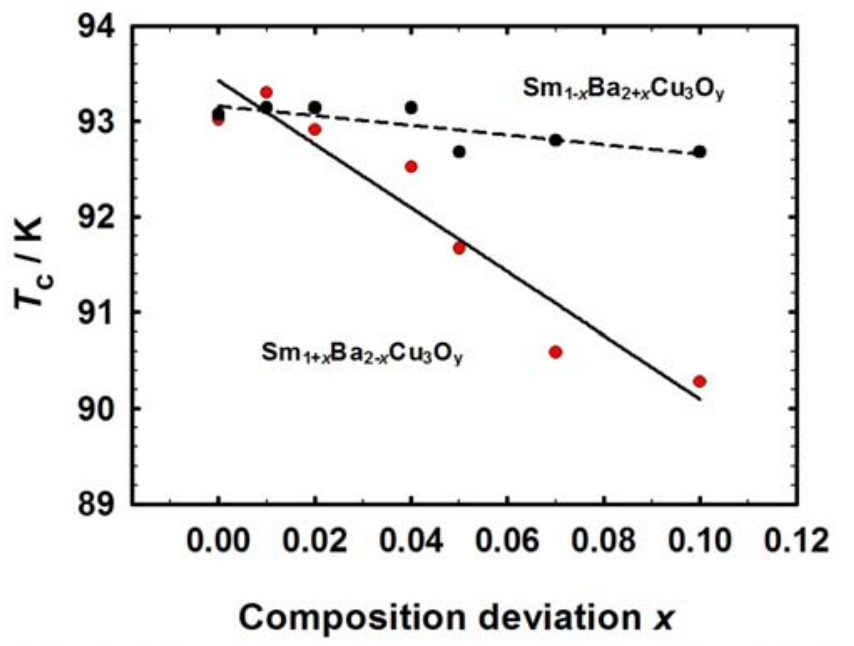

Fig.3. $T_{\mathrm{c}}$ vs. $x$ of the A and B samples. 
We can see that $\Delta T_{\mathrm{c}}$ of the Ba-rich $\mathrm{B}$ samples changes only slightly, while the A samples show the tendency of increasing $\Delta T_{\mathrm{c}}$ with increasing $x$. We think that local structure disordering effects start to dominate at higher composition deviations of $x$ of A samples as a result of the Sm substitution for $\mathrm{Ba}$. It is in accordance with the model

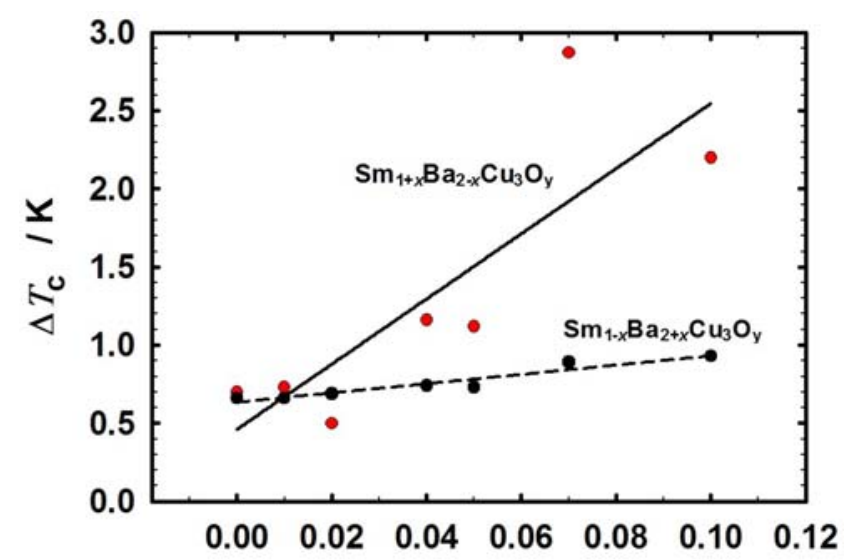

\section{Compositional deviation $x$}

Fig.4. $\Delta T_{\mathrm{c}}$ vs. $x$ of the $\mathrm{A}$ and $\mathrm{B}$ samples.

proposed by Kramer et al. [20, 21], according to which the increase of the Sm content of $x$ results in an increase of the total oxygen content and a decrease in the hole concentration in $\mathrm{Cu}-\mathrm{O}_{2}$ planes by donate electrons of the substitution. $\mathrm{Sm}^{3+}$ entering $\mathrm{Ba}^{2+}$ sites leads to a non-fourfold planar coordinated $\mathrm{Cu}$ on the chain sites either by the introduction of extra oxygen or oxygen reordering, relocation of oxygen from chain $\mathrm{O}(1)$ to the $\mathrm{O}(5)$ vacancy site. In the last case, the length of $\mathrm{Cu}-\mathrm{O}(1)$ chains decreases. The dependence of the critical temperature on the length of the $\mathrm{Cu}-\mathrm{O}(1)$ chains and processing temperature is well known [22-24]. These effects together determine the superconducting properties of A samples, e.g. $T_{c}, \Delta T_{c}$, and their degradation for higher $x$.

Hysteresis curves of $M$ vs. $H_{\mathrm{a}}$ for $\mathrm{A}$ and $\mathrm{B}$ samples are shown in Fig. 5 and 6, respectively.

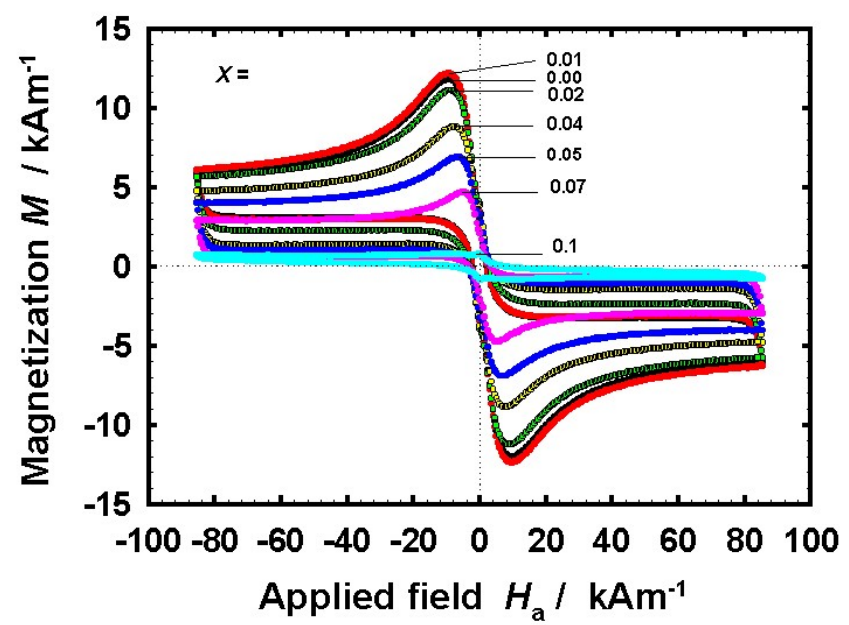

Fig.5. $M$ vs. $H_{\mathrm{a}}$ dependences of $\mathrm{Sm}_{1+x} \mathrm{Ba}_{2-x} \mathrm{Cu}_{3} \mathrm{O}_{7+\delta}$ samples with different $x$ values at $77 \mathrm{~K}$.
All samples show the Z-shaped magnetization curves typical for polycrystalline samples. We can see that magnetization, $M$, of A samples decreases with $x$ more rapidly than that of the B samples. Comparison of the maximum value of magnetization, $M_{\max }$, corresponding to the so-called low field (central) peak of A and B series samples for different $x$ is in Fig.7.

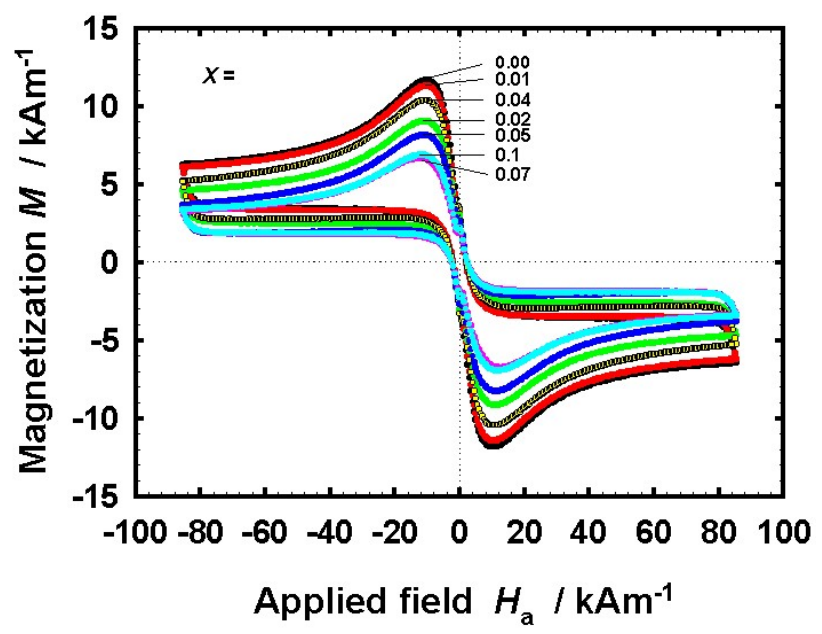

Fig.6. $M$ vs. $H_{\mathrm{a}}$ dependences of $\mathrm{Sm}_{1-x} \mathrm{Ba}_{2+\chi} \mathrm{Cu}_{3} \mathrm{O}_{7+\delta}$ samples with different $x$ values at $77 \mathrm{~K}$.

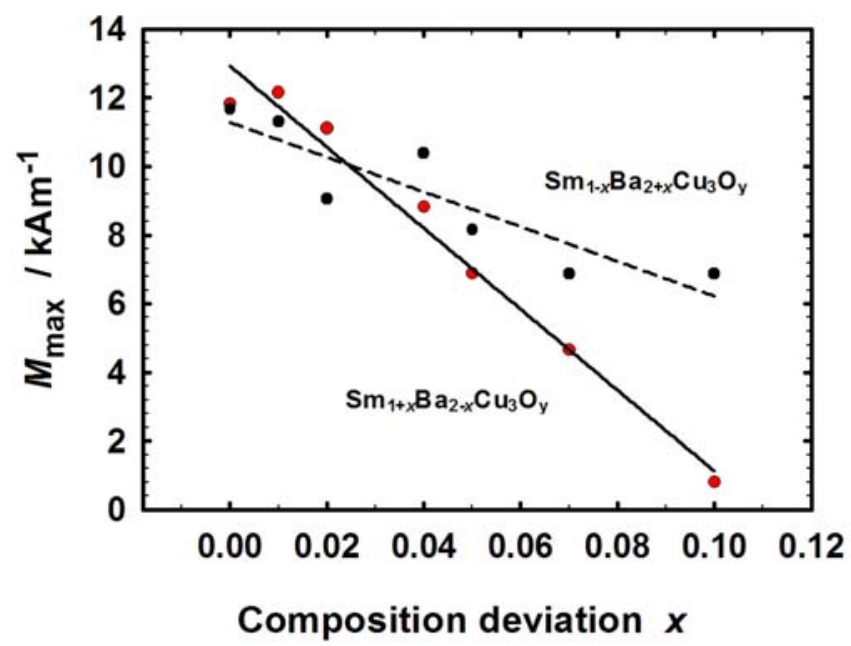

Fig.7. $M_{\max }$ vs. $x$ dependences of A and B series.

We also found that light Sm excess doping has a positive effect on the superconducting characteristics reflecting intergrain junction properties. We prepared also the $\mathrm{C}$ series of the $\mathrm{Sm}_{1+\chi} \mathrm{Ba}_{2} \mathrm{Cu}_{3} \mathrm{O}_{7+\delta}$ samples using the same processing conditions as in the case of $\mathrm{A}$ and $\mathrm{B}$ series. The dependences of their $T_{\mathrm{c}}$ and $H_{\mathrm{p} 1}$ on $x$ are in Fig. 8 and 9, respectively. The Sm excess values of $x=0.02-0.03$ well optimize $T_{\mathrm{c}}, \Delta T_{\mathrm{c}}, H_{\mathrm{p} 1}$ as well as $M$ of the $\mathrm{C}$ samples. 


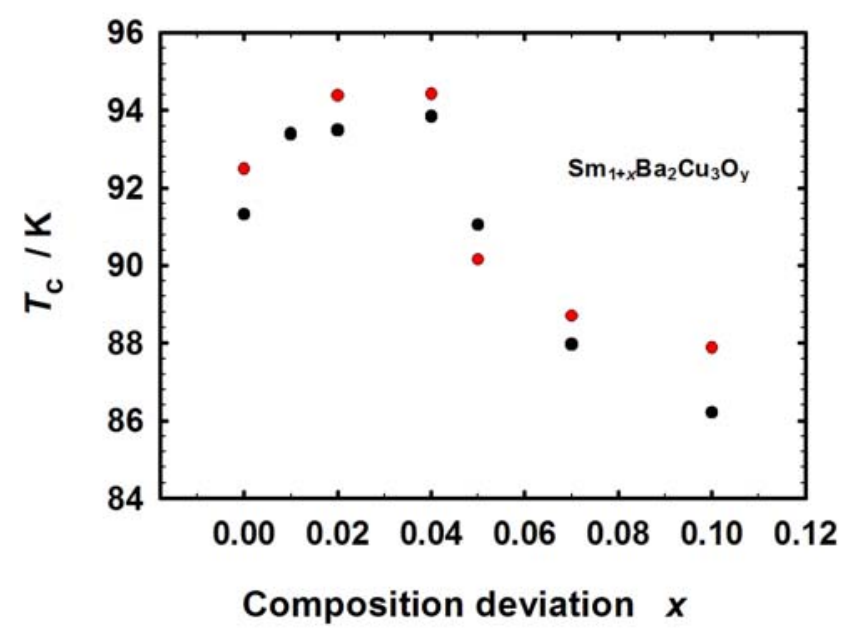

Fig.8. $T_{\text {c }}$ vs. $x$ of the $\mathrm{Sm}_{1+\chi} \mathrm{Ba}_{2} \mathrm{Cu}_{3} \mathrm{O}_{7+\delta}$ samples including parallel samples $(\bullet)$.

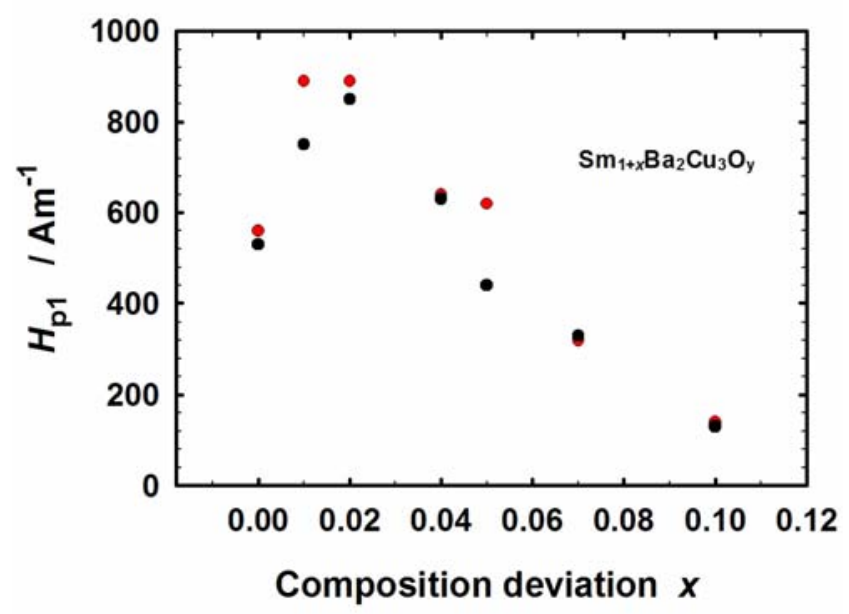

Fig.9. $H_{\mathrm{p} 1}$ vs. $x$ of the $\mathrm{Sm}_{1+\chi} \mathrm{Ba}_{2} \mathrm{Cu}_{3} \mathrm{O}_{7+\delta}$ samples including parallel samples $(\bullet)$.

$M$ vs. $H_{\mathrm{a}}$ magnetization hysteresis loops of the stoichiometry sample and non-stoichiometry A and B samples with $x=0.04$ are compared in Fig. 10 .

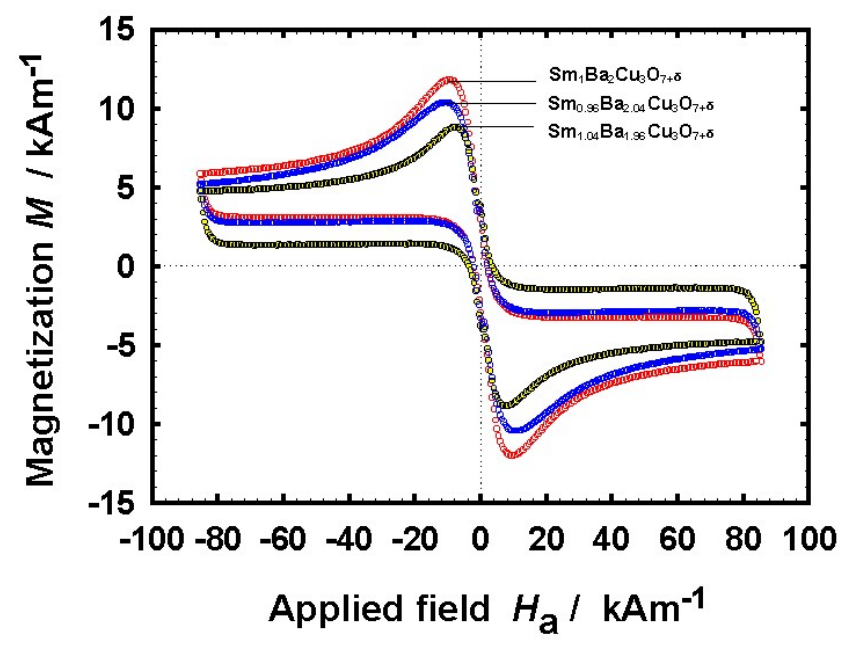

Fig.10. $M$ vs. $H_{\mathrm{a}}$ dependences of the stoichiometric $(x=0)$ and non-stoichiometric A and B samples with $x=0.04$ at $77 \mathrm{~K}$.
As expected, the $\mathrm{Ba}$ overdoping, $\left(\mathrm{Sm}_{0.96} \mathrm{Ba}_{2.04} \mathrm{Cu}_{3} \mathrm{O}_{7+\delta}\right.$ sample) as opposed to underdoping, has a positive effect on superconductivity and magnitude of magnetization, especially at higher doping levels. However, as it is evident from the figure, the Sm overdoped sample with composition deviation $x=0.04$ shows the largest width of the magnetization hysteresis, $\Delta M$, from all the studied samples at higher values of magnetic applied field, $H_{\mathrm{a}}$. We ascribe this to an increase of the flux pinning in the A sample with $x$ $=0.04$. We hope that in the A samples, non-stoichiometry, $x$, supports composition fluctuations (like nanoclusters in grains) and magnetic flux pinning is increased. On the other hand, the entering of $\mathrm{Sm}$ into $\mathrm{Ba}$ sites results in a certain degradation of the sample superconductivity, e.g. $T_{\mathrm{c}}, \Delta T_{\mathrm{c}}$ mainly at higher substitution levels. These two effects compete with each other. Our results show that the use of light non-stoichiometric precursors, e.g. $\mathrm{Sm}_{1.04} \mathrm{Ba}_{1.96} \mathrm{Cu}_{3} \mathrm{O}_{7+\delta}$ composition, could be useful in increasing of $\Delta M$ and therefore $j_{\mathrm{c}}$ in $\mathrm{Sm}-\mathrm{Ba}-\mathrm{Cu}-\mathrm{O}$ systems, since the width of the hysteresis of magnetization loops, $\Delta M$, indicates $j_{\mathrm{c}}$. We note that similar results were reported for non-stoichiometric thin films, too. For example, Sudoh et al. obtained high quality c-axis SBCO thin films from off-stoichiometric targets $(x=$ 0.04-0.12) with the highest $T_{\mathrm{c}}$ of $92.1 \mathrm{~K}$ from the target with $x=0.08$, [25]. Miyachi et al. [26] investigated an effect of the substitution of $\mathrm{Gd}$ into the $\mathrm{Ba}$ site in $\mathrm{Gd}_{1+\chi} \mathrm{Ba}_{2-\chi} \mathrm{Cu}_{3} \mathrm{O}_{6+\delta}$ thin film samples $(0 \leq x \leq 0.4)$. The highest values of $T_{\mathrm{c}}=$ $91.5 \mathrm{~K}$ and $j_{\mathrm{c}}=3 \mathrm{MA} \mathrm{cm}^{-2}$ were observed for $x=0.04$.

Of course, our results have to be verified on mono-domain or single crystal samples. We are currently working on it. However, please note that our studied samples were prepared at $\sim 1060{ }^{\circ} \mathrm{C}$ and that the volume density of all $\mathrm{A}$ and $B$ samples ranges from 6.45 to $6.73 \mathrm{~g} \mathrm{~cm}^{-3}$.

\section{CONCLUSION}

We studied light non-stoichiometry effects in $\mathrm{Sm}-\mathrm{Ba}-\mathrm{Cu}-$ $\mathrm{O}$ sintered samples. Two series of single-phase $\mathrm{Sm}_{1+x} \mathrm{Ba}_{2-}$ ${ }_{x} \mathrm{Cu}_{3} \mathrm{O}_{7+\delta}$ and $\mathrm{Sm}_{1-\chi} \mathrm{Ba}_{2+\chi} \mathrm{Cu}_{3} \mathrm{O}_{7+\delta}$ samples with $x$ from 0 to 0.1 were synthesized by the solid-state reaction method at $\sim$ $1060{ }^{\circ} \mathrm{C}$ in flowing oxygen. All samples show values of $T_{\mathrm{c}}>$ $90 \mathrm{~K}$ and the volume density from $6.45 \mathrm{~g} \mathrm{~cm}^{-3}$ to $6.73 \mathrm{~g} \mathrm{~cm}^{-}$ ${ }^{3}$. Ba excess $x$ in the $\mathrm{Sm}_{1-x} \mathrm{Ba}_{2+x} \mathrm{Cu}_{3} \mathrm{O}_{7+\delta}$ samples suppresses the substitution of $\mathrm{Sm}^{3+}$ for $\mathrm{Ba}^{2+}$ and thereby reduces degradation of superconducting properties, such as $T_{\mathrm{c}}, \Delta T_{\mathrm{c}}$, and the maximal value of volume magnetization when compared to Sm excess of $x$ in $\mathrm{Sm}_{1+\chi} \mathrm{Ba}_{2-x} \mathrm{Cu}_{3} \mathrm{O}_{7+\delta}$ samples at higher values of $x$. However, the Sm excess sample with composition deviation $x=0.04$ shows the highest hysteresis of $\Delta M$ from all the studied samples at higher values of the applied magnetic field. The results show that the use of light non-stoichiometric precursors, e.g. of the $\mathrm{Sm}_{1.04} \mathrm{Ba}_{1.96}$ $\mathrm{Cu}_{3} \mathrm{O}_{7+\delta}$ composition, could by useful in increasing of $j_{\mathrm{c}}$ in $\mathrm{Sm}-\mathrm{Ba}-\mathrm{Cu}-\mathrm{O}$ systems. In addition, we prepared also the $\mathrm{Sm}_{1+\chi} \mathrm{Ba}_{2} \mathrm{Cu}_{3} \mathrm{O}_{7+\delta}$ samples with $x$ from 0 to 0.1 using the same processing conditions as in the case of $\mathrm{A}$ and $\mathrm{B}$ series. The Sm excess values of $x=0.02-0.03$ well optimize $T_{\mathrm{c}}$, $\Delta T_{\mathrm{c}}, H_{\mathrm{p} 1}$ as well as the volume magnetization of the $\mathrm{Sm}_{1+\chi} \mathrm{Ba}_{2} \mathrm{Cu}_{3} \mathrm{O}_{7+\delta}$ samples. 


\section{ACKNOWLEDGEMENT}

This work was supported by the Agency of the Ministry of Education of the Slovak Republic for the Structural Funds of the EU, Operational Programme Research and Development (OPVaV-2008/4.1/01-SORO), Project Code 262401200 11.

\section{REFERENCES}

[1] Osabe, G., Takizawa, T., Yoo, S.I., Sakai, N., Higuchi, T., Murakami, M. (1999). Studies of the $\mathrm{Nd}_{1+\mathrm{x}} \mathrm{Ba}_{2-\mathrm{x}} \mathrm{Cu}_{3} \mathrm{O}_{\mathrm{y}}$ solid solutions. Mater. Sci. Eng. BSolid State, 65 (1), 11-16.

[2] Xu, Y., Kramer, M.J., Dennis, K.W., Wu, H., O`Connor, A., McCallum, R.W., Malik, S.K., Yelon, W.B. (2000). Substitution for Ba by Pr, La, and Eu in $\mathrm{Eu}\left(\mathrm{Ba}_{1-\mathrm{x}} \mathrm{R}_{\mathrm{x}}\right)_{2} \mathrm{Cu}_{3} \mathrm{O}_{7+\delta}$ solid solutions. Physica C, 333 (3-4), 195-206.

[3] Li, Y., Liu, Y., Duan, R., Xiong, X., Wang, B., Cao, G., Wei, L., Zheng, D.N., Zhao, Z.X., Ross, J.H. (2004). Positron annihilation study of the $\mathrm{O}-\mathrm{T}$ phase transition for $\mathrm{Eu}_{1+\mathrm{x}} \mathrm{Ba}_{2-\mathrm{x}} \mathrm{Cu}_{3} \mathrm{O}_{7-\delta}$ superconductors. Physica C, 402 (1-2), 179-187.

[4] Sano, M., Hayakawa, Y., Kumagawa, M. (1996). The effect of the substitution of $\mathrm{Sm}$ for $\mathrm{Ba}$ on the superconductor $\mathrm{SmBa}_{2} \mathrm{Cu}_{3} \mathrm{O}_{\mathrm{y}}$. Superconduct. Sci. Technol., 9 (6), 478-482.

[5] Van Driessche, I., Schoofs, B., Bruneel, E., Hoste, S. (2004). The effect of processing conditions on the properties of spray dried $\mathrm{Nd}_{1} \mathrm{Ba}_{2} \mathrm{Cu}_{3} \mathrm{O}_{y} / \mathrm{Ag}$ composite superconductors. J. Eur. Ceram. Soc., 24 (6), 18231826.

[6] Drozd, V.A., Baginski, I.L., Nedilko, S.A., Mel'nikov, V.S. (2004). Oxygen stoichiometry and structural parameters of $\mathrm{Sm}_{1+\mathrm{x}} \mathrm{Ba}_{2-\mathrm{x}} \mathrm{Cu}_{3} \mathrm{O}_{\mathrm{y}}$ solid solutions versus composition and temperature. J. Alloys Compounds, 384 (1-2), 44-50.

[7] Koblischka, M.R., Winer, M., Hartman, U. (2007). Nanostripe structures in $\mathrm{SmBa}_{2} \mathrm{Cu}_{3} \mathrm{O}_{x}$ superconductors. Superconduct. Sci. Technol., 20 (7), 681-686.

[8] Hu, A., Koblischka, M.R., Yao, X., Zhou, H., Winter, M., Hartmann, U., Murakami, M. (2006). Recent progress on compositional nanostripes of $\mathrm{REBa}_{2} \mathrm{Cu}_{3} \mathrm{O}_{7-\delta}(\mathrm{RE}=\mathrm{Sm}, \mathrm{Eu}, \mathrm{Gd})$ superconductors. Superconduct. Sci. Technol., 19 (7), S580-S584.

[9] Koblischka, M.R., Winter, M., Das, P., KoblischkaVeneva, A., Muralidhar, M., Wolf, T., Babu, N.H., Turner, S., Tendeloo, G., Hartmann, U. (2009). Observation of nanostripes and -clusters in $(\mathrm{Nd}$, EuGd) $\mathrm{Ba}_{2} \mathrm{Cu}_{3} \mathrm{O}_{\mathrm{x}}$ superconductors. Physica C, 469 (4), 168-176.

[10] Oh, S.S., Ha, H.S., Kim, H.S., Ko, R.K., Song, K.J., Ha, D.W., Kim, T.H., Lee, N.J., Youm, D., Yang, J.S., Kim, H.K., Yu, K.K., Moon, S.H., Ko, K.P., Yoo, S.I. (2008). Development of long-length SmBCO coated conductors using a batch-type reactive co-evaporation method. Superconduct. Sci. Technol., 21 (3), 034003-1-6.
[11] Wang, H., Serquis, A., Maiorov, B., Civale, L., Jia, Q.X., Arendt, P.N., Foltyn, S.R., MacManus-Driscoll, J.L., Zhang, X. (2006). Microstructure and transport properties of Y-rich $\mathrm{YBa}_{2} \mathrm{Cu}_{3} \mathrm{O}_{7-\delta}$ thin films. J. Appl. Phys., 100 (5), 053904-1-4.

[12] Holesinger, T.G., Civale, L., Maiorov, B., Feldmann, D.M., Coulter, J.Y., Miller, D.J., Maroni, V.A., Chen, Z., Larbalestier, D.C., Feenstra, R., Li, X., Huang, Y., Kodenkandath, T., Zhang, W., Rupich, M.W., Malozemoff, A.P. (2008). Progress in nanoengineered microstructures for tunable high-current, hightemperature superconducting wires. Advan. Mater., 20 (3), 391-407.

[13] Mele, P., Matsumoto, K., Horide, T., Ichinose, A., Mukaida, M., Yoshida, Y., Horii, S. (2007). Insertion of nanoparticulate artificial pinning centres in $\mathrm{YBa}_{2} \mathrm{Cu}_{3} \mathrm{O}_{7-\mathrm{x}}$ films by laser ablation of a $\mathrm{Y}_{2} \mathrm{O}_{3}-$ surface modified target. Superconduct. Sci. Technol., 20 (7), 616-620.

[14] Plackowski, T., Sulkowski, C., Bukowski, Z., Wlosewicz, D., Rogacki, K. (1995). Electronic structure parameters of $\mathrm{Sm}_{1+\mathrm{x}} \mathrm{Ba}_{2-\mathrm{x}} \mathrm{Cu}_{3} \mathrm{O}_{\mathrm{y}}$ solid solution of orthorhombic and tetragonal structure. Physica C, 254 (3-4), 331-341.

[15] Kameneva, M.Y., Kozeeva, L.P., Blinov, A.G., Kuratieva, N.V., Fedorov, V.E. (2009). Preparation of polycrystalline samples of solid solutions $\mathrm{Sm}_{1+\mathrm{x}} \mathrm{Ba}_{2-}$ ${ }_{x} \mathrm{Cu}_{3} \mathrm{O}_{6+y}(x=0.0-0.7)$ and a study of their structural and superconducting properties. J. Ceram. Proc. Res., 10 (1), 61-65.

[16] Cigáň, A., Maňka, J., Polovková, J., Majerová, M., Kopčok, M., Van Driessche, I., Zrubec, V. (2008). Study of light nonstoichiometry in Eu-Ba-Cu-O systems. J. Phys. Conf. Ser., 97, art. no. 012184.

[17] Vermeir, P., Cardinael, I., Schaubroeck, J., Verbeken, K., Bäcker, M., Petra Lommens, P., Knaepen, W., D’haen, J., De Buysser, K., Van Driessche, I. (2010). Elucidation of the mechanism in fluorine-free prepared $\mathrm{YBa}_{2} \mathrm{Cu}_{3} \mathrm{O}_{7-\delta}$ coatings. Inorg. Chem., 49 (10), 4471-4477.

[18] Zrubec, V., Cigáň, A., Maňka, J. (1994). Simplified fast method for magnetic characteristics measurement of the $\mathrm{HT}_{\mathrm{c}}$ superconducting materials. Physica $C, 223$ (1-2), 90-94.

[19] Chen, J.M., Liu, R.S., Lee, J.M., Lu, K.T., Yang, T.J., Kramer, M.J., McCallum, R.W. (2006). Highresolution XANES study of $\mathrm{Eu}\left(\mathrm{Ba}_{1-\mathrm{x}} \mathrm{R}_{\mathrm{x}}\right)_{2} \mathrm{Cu}_{3} \mathrm{O}_{7+\delta}(\mathrm{R}$ $=\mathrm{Eu}$, Pr). New J. Phys., 8 (9), 215-1-9.

[20] Kramer, M.J., Yoo, S.I., McCallum, R.W., Yelon, W.B., Xie, H., Allenspach, P. (1994). Hole filling, charge transfer and superconductivity in $\mathrm{Nd}_{1+\mathrm{x}} \mathrm{Ba}_{2-\mathrm{x}} \mathrm{Cu}_{3} \mathrm{O}_{7+\delta}$. Physica C, 219 (1-2), 145-155.

[21] Chen, J.M., Liu, R.G., Chung, S.C., Liu, R.S., Kramer, M.J., Dennis, K.W., McCallum, R.W. (1997). Soft x-ray absorption spectroscopy of $\mathrm{Nd}_{1+\mathrm{x}} \mathrm{Ba}_{2-\mathrm{x}} \mathrm{Cu}_{3} \mathrm{O}_{7+\delta}(x=0-0.6)$. Phys. Rev. B, 55 (5), 3186-3191. 
[22] Tallon, J.T. (2005). Oxygen in high- $T_{\mathrm{c}}$ cuprate superconductors. In Narlikar, A.V. (ed.) Frontiers in Superconducting Materials. Springer-Verlag, 295328.

[23] Andersen, N.H., Zimmermann, M., Frello, T., Käll, M., Monster, D., Lindgard, P.A., Madsen, J., Niemöller, T., Poulsen, H.F., Schmidt, O., Schneider, J.R., Wolf, T., Dosanjh, P., Liang, R., Hardy, W.N. (1999). Superstructure formation and the structural phase diagram of $\mathrm{YBa}_{2} \mathrm{Cu}_{3} \mathrm{O}_{6+\mathrm{x}}$. Physica $C, 317-318$ (1), 259-269.

[24] Scavini, M., Daldosso, D., Cappelli, S., Oliva, C., Brunelli, M., Ferrero, C., Lascialfari, A. (2006). Unravelling the role of $\mathrm{Cu}-\mathrm{O}$ chain length on the superconducting properties of $\mathrm{SmBa}_{2} \mathrm{Cu}_{3} \mathrm{O}_{6+\delta}$ via $\mathrm{Al}$ doping and clustering. Europhys. Lett., 76 (3), 443449.
[25] Sudoh, K., Yoshida, Y., Takai, Y. (2004). Effect of deposition conditions and solid solution on the $\mathrm{Sm}_{1+\mathrm{x}} \mathrm{Ba}_{2-\mathrm{x}} \mathrm{Cu}_{3} \mathrm{O}_{6+\delta}$ thin films prepared by pulsed laser deposition. Physica C, 384 (1-2), 178-184.

[26] Miyachi, K., Sudoh, K., Ichino, Y., Yoshida, Y., Takai, Y. (2003). The effect of the substitution of Gd for $\mathrm{Ba}$ site on $\mathrm{Gd}_{1+\mathrm{x}} \mathrm{Ba}_{2-\mathrm{x}} \mathrm{Cu}_{3} \mathrm{O}_{6+\delta}$ thin films. Physica C, 392-396 (Part 1), 1261-1264.

Received December 21, 2010. Accepted March 22, 2011. 